WANG Tiemin, ZHOU Jie

\title{
Strategic choices of firms in expanding overseas business
}

\section{-A case study of Pfizer's production scope evolution in China (1993-2002)}

\section{(C) Higher Education Press and Springer-Verlag 2008}

\begin{abstract}
Based on a case study of Pfizer's production scope evolution in China from 1993 to 2002, we propose that MNCs usually have to face dual pressures of keeping integration among global businesses on the one hand, and remaining responsive to local market conditions on the other. When there is large discrepancy between the two, due to the bounded rationality of the decision-makers, the development paths of the subsidiaries are likely to exhibit recursive pattern, instead of the sequential mode as suggested in the extant literature. On the other hand, we argue that companies can make strategic choices to facilitate the development of their overseas subsidiaries. By the adjustment of the strategic parameters pertaining to the content and processes of their development paths, companies can accumulate knowledge about the local market and strike a balance between the dual pressures they have to face. The implication of our study for the indigenous Chinese companies in their international expansion is that when facing unfamiliar business environment in overseas market, paying attention to the idiosyncratic local market condition and keeping strategic flexibility are pivotal to their success.
\end{abstract}

Keywords multinational corporations(MNCs), international expansion, subsidiary development, strategic choices

Translated from Guanli shijie 管理世界(Management World), 2005(10): 123-138

WANG Tiemin $(\square)$

Guanghua School of Management, Peking University, Bejing 100871, China

E-mail: twang@gsm.pku.edu.cn

ZHOU Jie

School of Public Policy and Management, Tsinghua University, Bejing 100084, China 
摘要 通过对辉瑞制药中国公司在1993到2002年期间在华生产范围发展路径的描述 和分析, 提出两个观点。一是在跨国经营中企业通常面临保持公司在全球的业务整 合以及适应当地市场具体条件的双重压力, 当两者之间存在较大差异时, 由于决策 者的认知受有限理性的制约, 海外子公司的业务并不会按现有文献中所提出的按母 公司已有业务从强到弱顺序发展, 而是呈现迁回发展的路径。二是企业可以通过对 战略变量的参数选择来调节其海外子公司的业务发展, 而这样的参数调节过程有助 于企业通过试探逐渐积累关于当地市场的知识, 从而在跨国经营的双重压力中获取 平衡。对中国企业开展国际化经营提供的启示是: 当企业在海外扩张中面临陌生的环 境时，对当地市场的特性给予足够的关注并保持战略上的灵活性是取得成功的关键。

\section{关键词 跨国公司, 海外扩张, 子公司发展, 战略选择}

\section{Introduction}

One trend in international business is an increasing integration of emerging markets into the world economy. This is not only reflected in the increasingly active investment and business activities of multinational corporations (MNCs) in emerging markets, such as India, China and Eastern Europe, but also in the surging wave of the international expansion of more and more indigenous firms from these markets. How do MNC overseas subsidiaries evolve over time? What are the main factors that affect their evolution? What kind of strategic choices can MNCs make to adjust the evolutionary path of their overseas subsidiaries? These issues are important not only for the MNCs and their subsidiaries, but also for the local companies and government in the host countries. Understanding the development pattern of MNCs' overseas subsidiaries can not only help local firms in the host country understand the competitive dynamics in their head-on competitions with the MNCs, but also bring insights to the local firms in their own internationalization processes. Hence, we try to address the above research questions by a case study on Pfizer's subsidiary in China, Pfizer Pharmaceuticals Ltd. (China), and its production scope evolution during the period of 1993-2002. Our finding suggests that, in its operation in China, Pfizer faced significant challenges of keeping corporate-wide global integration on the one hand, and local responsiveness on the other, but it managed to achieve stable growth and superior performance by keeping flexibility in its product scope development, thus struck a balance between the two conflicting dual pressures. Based on the Pfizer case, we further identify the generic parameters characterizing its product launching strategy, and highlight the strategic choices managers could make, by combining the different parameters, in adjusting the content and processes of subsidiaries' production scope evolution. 
The primary contribution we want to make in this paper is to help MNC managers make more informed strategic decisions, by paying attention to the generic parameters we identified based on the Pfizer case, so that they can deal with the conflicting pressures of keeping global integration and local responsiveness simultaneously. First, our findings also contribute to the subsidiary evolution literature(Birkinshaw, 1996; Birkinshaw and Hood, 1998; Chang and Rosenzweig, 1998b) by showing that, when there is large discrepancy between MNC's home market condition and the host country market condition, subsidiary evolution in the host country will exhibit a recursive pattern, rather than the sequential mode that is predicted by Chang et. al. based on their study of the foreign market entries of Japanese MNCs(Chang,1996; Chang and Rosenzweig, 1998a). In our view, the recursive pattern reflects the bounded rationality of the decision-makers (Simon,1955), and complements the sequential mode in our understanding of MNC subsidiary evolution in different contexts. Second, in terms of specific research on MNC subsidiary development in China, attentions in prior research were mainly directed to the strategic role of subsidiaries in the MNCs (Zhao, 2001; 2002), and the R\&D investment and activities of MNCs(Xue et. al., 1999; 2001; 2002; Jiang and Feng, 2000). Less has been studied on the manufacturing activities of MNC subsidiaries in China. However, as China is becoming the world workshop, manufacturing activities account for an important portion of the inward FDI to China. We chose to address this issue by tracing and analyzing the production scope evolution of Pfizer Pharmaceuticals Ltd. (China). Our aim is to shed light on the evolution of the core business content of MNC subsidiaries in the Chinese market. Finally, in terms of research method, while extant studies on subsidiary development in China mainly used questionnaire data, we adopted a longitudinal research approach in our case study, which suits the purpose of studying the evolutionary path of MNC subsidiaries.

We provide a critical review on the literature related with MNCs' international expansion and subsidiary evolution. We then introduce our research setting and provide detailed information on Pfizer Pharmaceuticals Ltd. (China) and its production scope evolution during 1993-2002. Findings emerged from the case and their theoretical and managerial implications are further discussed. In particular, we elaborate on the relevance of our findings to the indigenous Chinese firms in their internationalization.

\section{Literature review and research motivations}

We provide a review of three literature streams that are closely related to the central issue of our research, which include studies on the internationalization of 
firms, MNC subsidiary evolution, and the business operation of MNCs in China.

Earlier research in the international business area focused on the driving forces of FDI and the emergence of MNCs. Dunning's Eclectic Paradigm of international production, which was first presented in the Nobel symposium in 1976, integrated three main factors, including the ownership advantages, locational advantages and internalization advantages. The OLI framework assists us in analyzing the rationale for the emergence of FDI and MNCs (Dunning, 1988, 2002). Subsequent research paid more attention to the entry strategies of firms in their internationalization processes, including their choice of ownership mode, locational mode, and the temporal pattern of MNC's international expansion et. al. Among the studies on the ownership mode of MNCs entry strategies, researchers paid special attention to the comparison among greenfield start-ups, acquisitions, and joint ventures. They also examined the performance consequences of these alternative modes (Hannart and Park, 1993; Barkema and Vermeulen, 1998; Delios and Henisz, 2000). Among the studies on the locational choice of direct foreign investment by MNCs, one main focus is to analyze the economic and political conditions of different countries (Spar, 2001; Globerman and Shapiro, 2003), and decompose uncertainty into different types, e.g. those related with the policy uncertainty that is specific to the host country, and firm-specific uncertainty that is related to a firm's prior experiences with the host country market. Impact of the different types of uncertainties on MNCs' locational choice of foreign entries was further investigated (Henisz \& Delios, 2001; Delios \& Henisz, 2003). With regard to the research on the temporal pattern of MNCs' consecutive foreign investments, researchers find significant linkage between the pace, scope and rhythm of MNCs' international expansion and their profitability (Vermeulen and Barkema, 2002).

While the internationalization and entry mode literature stream addresses the strategic issues related to the initial stage of $\mathrm{MNCs}$ ' international business operation, the subsidiary development literature stream deals with MNC operation and performance after their initial entries. A common theme in the literature is the presence of the conflicting dual pressures imposed on subsidiaries or MNC head offices (Prahalad and Doz, 1987; Bartlett and Ghoshal, 1989), i.e. how to keep consistency within the corporate context and maintain local responsiveness. On the one hand, MNCs emerge and exist because of market failure and the organizational strength in coordination and knowledge management (Kogut and Zander, 1993), hence maintaining global integration and leveraging on corporate core competence are important for subsidiaries. On the other hand, subsidiaries operate within the context of local market, which inevitably involves various exchange relationships of capital resources and human resources et. al. between the organizations and their environment. As the resource dependence theory (Pfeffer and Salancik, 1978) suggests, responsiveness to host country 
conditions is key for the development of MNC subsidiaries. When the two demands differ, MNCs have to deal with the conflicting pressures arising from them. Empirical studies on subsidiary development paid special attention to the charter change of subsidiaries. Birkinshaw (1996) proposed a life cycle model based on his study on the world product mandates of six Canadian subsidiaries of U.S. owned MNCs, and used the model to explore the factors associated with the gain, development, and loss of mandates by subsidiaries. Building on the case study, Birkinshaw and Hood (1998) further identified five generic subsidiary development processes, based on the interactions between subsidiary capability development and its charter change. In addition, Chang and Rosenzwig (1998b) carried out an in-depth case study of SONY and its subsidiary development in the U.S. Based on their Further study of the line of business entries of Japanese MNCs and European MNCs in the U.S. during 1976 to 1989, Chang concluded that MNCs followed a sequential pattern in their line of business entries (Chang, 1995, Chang and Rosenzwig, 1998a). According to Chang's sequential entry mode, MNCs are more likely to invest in their core business with larger size and/or those having competitive advantage over the local industry players in terms of R\&D or advertising intensity. The larger the size of the business, or the stronger the relative advantage of the $\mathrm{MNC}$ in comparison with the local competitors in the business, the more likely MNCs will make the business entry in their foreign subsidiaries.

Relevant publications in Chinese journals have examined the patterns of inward FDI to China and MNC activities, including the impact of FDI on the Chinese economy, MNCs' entry mode, and their competitive strategy in the Chinese market. In terms of the impact of inward FDI on Chinese economy, Wang, Jiang and $\mathrm{Lu}(2000 \mathrm{a}, 2000 \mathrm{~b})$ analyzed the effect of inward FDI by MNCs listed in the Fortune 500 in 1998, and found positive effects, such as consolidating the fragmented industry structure, promoting technology upgrading and the integration of China with the world economy. Jiang(2002) narrowed her analysis to MNCs in three industries characterized by their different levels of R\&D intensity and economic scale, i.e., automobile, telecommunications equipment and detergent. Her main finding was that the market structure of these three industries changed as more MNCs entered into China, and the foreign invested enterprises contributed to the formation of more competitive market structure. With regard to the entry mode of MNCs into China, Qiu and Yu (2003) traced the inward FDI to China during 1993 to 2002, and found that, with the market conditions getting more suitable for international business and with the MNCs getting more experienced with the Chinese market, the proportion of annual investment in joint ventures in the annual total inward FDI to China dropped steadily over the ten-year study period, whereas the proportion of investment on wholly owned subsidiaries of the MNCs increased. With regard to the operation of MNCs in China, Wu and Yuan(2003) discussed 
the competitive strategy of MNCs in the Chinese consumer electronics industry, and summarized the implications for Chinese firms. Xue et. al. (Xue and Wang, 1999; Xue, Wang and Shen, 2001; Xue, Shen and Wang, 2002) focused on examining the phenomenon of R\&D institutions set by MNCs in China. Based on telephone and mail survey of 299 R\&D establishments of the 1000 largest companies listed in Business Week in 1999, they analyzed the factors that led to MNCs' investment on setting up R\&D institutions and the distribution of the R\&D investment across industries. In addition, Zhao(2001, 2002) analyzed the evolution of the strategic roles of MNC subsidiaries in China. Based on a factor analysis of the survey data containing more than 140 MNC subsidiaries in China, he found that the initial strategic roles of the subsidiaries belong to one of the following four types, i.e., market-expansion(76\%), production-base $(19 \%)$, risk-aversion( $3 \%$ ), and knowledge-seeking( $2 \%)$. His findings also indicated that, although the initial strategic roles are often assigned to the subsidiaries, as subsidiaries evolve, their strategic roles often change between the different types over time. Hence subsidiaries development follows an interactive growth mode, where the investment motivation of MNCS determines the strategic role of the subsidiaries, the strategic role of the subsidiaries determines their strategy, and the strategy in turn influences subsidiary role within the MNCs.

As indicated in the above literature review, research in the international academic society focused more on studying the strategy and performance of MNCs and their overseas subsidiaries in developed countries. Much less has been investigated in terms of MNC subsidiaries' evolution in host countries where social economic conditions differ considerably from their home countries. On the other hand, Chinese business scholars paid more attention to MNCs operations in China. Although, the empirical work generated rich insights into FDI and MNC activities in China, the linkage between the empirical findings and international business theory need to be further elaborated. How to use the context of Chinese market to test and expand IB theory presents an exciting research area. Our study is aimed at addressing the issue by examining one aspect of subsidiaries' evolution (i.e. production scope evolution). And we hope to shed light on the role of management choices in coping with the conflicting forces of the dual pressures faced by the MNC subsidiaries in trying to strike a balance between keeping global integration within the MNCs and local responsiveness.

\section{The case study}

\subsection{The research setting-Chinese pharmaceutical industry}

Chinese pharmaceutical industry is one of the earliest industries in China that 
were opened up to foreign investors. Nationwide expenditure on pharmaceuticals in China increased from 35 billion Yuan (equivalent to 4.2 billion U.S. dollars) at the end of the 1980s to 125 billion Yuan (15 billion US dollars) in 2002. Attracted by the remarkable market growth rate and the huge potential market capacity based on China's population base, most of the top-ranked MNCs in the world pharmaceutical industry set up subsidiaries in China. The first wave of MNC's entries occurred in the earlier 1980s. Foreign invested joint ventures established in that period included Tianjin Otsuka, Xi'an Jansen, Tianjin SmithKline Beecham, Shanghai Bristol Myers Squibb (BMS), Wuxi Pharmacia and Beijing Ciba-Geigyi. These first-movers enjoyed hefty profits and achieved more than $40 \%$ annual sales growth rate. This led to the second wave of entries by industrial giants such as Pfizer, Merck, and Glaxo in the earlier 1990s. Approximately one billion US dollars had been actually invested during 1990-1995 (with 1.5 billion US dollars as appeared in contracts). Although the Chinese pharmaceutical market grew rapidly, competition also intensified. On one hand, this is because there are more MNC's setting up subsidiaries and competing in the Chinese pharmaceutical market, and on the other hand, domestic pharmaceutical producers also grew vigorously and strove for keeping their market share by selling cheap but effective generic drugs. Policy reforms aimed at cost containment in the national heath-care reimbursement system established since 1998 also added pressures to MNC subsidiaries, making them shift even more from import to local production based strategies.

According to the Drug Administrative Law (DAL) in China, drug production follows a strict licensing procedure, with the State Food and Drug Administration $(\mathrm{SFDA})^{1}$ being in charge. The licensing system not only applies to each company if they wanted to be a drug producer, but also to each drug a producer wanted to produce once a company obtained the company license as a drug-producer. For MNC subsidiaries that would like to produce drugs in China, they have two options. One is to produce new drugs that have not yet been produced in China (i.e., a drug that is still under Patent protection or an off-patent drug that has not been produced in China). The other is to produce generic drugs that have already been produced in China. Both options are feasible and are actually adopted by MNCs, but they require different application procedures. Needless to say, applying for new drug approval and the corresponding production license is

${ }^{1}$ Before 1998, SPAC (State Pharmaceutical Administration of China) and the Ministry of Health (MOH) were mainly in charge of chemical drug administration. In 1998, the State Drug Administration (SDA) started operation. SDA replaced the former SPAC and expanded its administrative roles to further include those areas that were previously under the regulation of MOH. Since 2003, SDA was further reorganized and expanded as the State Food and Drug Administration (SFDA). Currently SFDA is in charge of drug administration, including chemical drugs (i.e., western style medicines) and traditional Chinese medicines, in China. 
much more demanding, in terms of time and the financial resource, than applying for the production license of a generic drug. Although the process is demanding, MNCs' subsidiaries often choose to go through the new drug application procedure to seek a certain level of protection for their intellectual property rights and therefore avoid the cutthroat price competition in the low-margin market segment of generic drugs. Precisely, because applying for new drug approval and drug production licenses require considerable resource commitment of MNCs, their choice of producing any particular drug in China is not likely to be an ad hoc decision. Rather, it often reflects strategic considerations of the MNCs and/or the subsidiaries. Hence, by tracing the product licenses MNC subsidiaries obtained from SFDA over time, we can map the evolution of their production scope in China.

\subsection{Sample selection and data}

Among the many multinational pharmaceutical companies that had set up subsidiaries in China, we chose Pfizer for our case study based on the following considerations. First, Pfizer set up its subsidiary in China in 1993, which is in the middle of the second wave of MNC entries to the Chinese pharmaceutical industry. Unlike those early entrants that captured the window of opportunity and enjoyed the first-mover advantage, Pfizer, as one of the second-movers, had to compete in China both with the indigenous Chinese drug producers and those earlier MNC entrants. Hence, the competition dynamics the late entrants had to face presented a more "typical" scenario for MNC subsidiaries. Second, entering the 1990s, drug administrative system, the institutional environment, and market conditions in the Chinese pharmaceutical industry became more stable for foreign investors. Hence, local market conditions are more likely to be an aspect for management consideration in MNC subsidiary evolution. In other words, the research setting allows us to explore if there were dual pressures for MNC subsidiaries that operated in China and how they responded to the pressures.

In this study, we focus on examining one aspect of MNC subsidiary evolution in China, i.e. its production scope evolution. Although production is just one type of business activities in MNCs' global value chain systems, it usually is the main type of business activities for MNC subsidiaries that operates in China. As Zhao (2001, 2002) found in his survey research, there are two main motivational drivers for MNCs to set up subsidiaries in China. One is that China is becoming a workshop for the world. Many MNCs do not engage in production any more, rather, they outsource from China and other countries with more competitive costs of labor and raw materials. Another motivational driver is that the huge population base of China and the potential market size are irresistible for many market-seeking MNCs, particularly for those companies whose revenue (from 
selling products or providing services) are proportional to the population, e.g., fast food and beverage, consumer electronics, and pharmaceuticals. For the MNCs, to really benefit from the fast growing Chinese market, they have to tailor their products to suit the consumption level of Chinese consumers, which is increasing rapidly, but still lower than that of the Western consumers. In other words, those market-seeking MNCs need to be cost competitive. As a result, they often have to locate their production base in China as well. For both types of MNC subsidiaries, production and the scope of production become an important aspect of subsidiary operation in China.

Linking back to the research setting of our study, i.e., the Chinese pharmaceutical industry, we define the production scope of a MNC subsidiary in China as the set of drugs that the subsidiary has been approved of the corresponding production licenses by the SFDA of China (or its precursors), including packaging of imported drug ingredients. According to the drug administrative law in China and the SFDA regulation, drugs that contain the same ingredients, but have different preparation forms (e.g., capsules or pills) or dosages (e.g., $1 \%$ or $5 \%$ injections) require separate licenses. Thus, each drug production license contains specific information on the ingredients, preparation form and dosage of the drug. We did not include those purely imported drugs by Pfizer into the production scope of the subsidiary, although it complements the locally produced drugs in the composition of Pfizer's business activities in China. We did have data on the registered drug imports of Pfizer to China during our study period, 1993-2002. Our analysis showed that there were considerable overlaps between Pfizer's drug list for local production and that for pure imports. This is because the registration procedure of importing drugs is speedier for launching products to market than applying for local production. Hence, most MNCs started their business in China by selling imported drugs, and then replaced them by locally produced drugs for lower costs and quicker responses to local demand. We chose to capture Pfizer's business evolution in China by mapping the changes of its locally produced drugs, because the strict licensing procedure for local production demands more commitment of MNCs, and the decisions, on which drug to produce locally and when, are more likely to reflect management cognitions.

The study period for Pfizer's production scope evolution is from 1993(the year when Pfizer Pharmaceuticals Ltd. was first founded in Dalian) to 2002. Information mainly covers the following three aspects, i.e., Pfizer Pharmaceuticals Ltd.(China)'s product licenses approved by SFDA, Pfizer corporate level product and sales information, and the market demand for prescription drugs in China. For the subsidiary product licenses, information was obtained from the drug production licenses database maintained by SFDA of China. For Pfizer corporate information, we collected its annual reports through Mergent Online. For local market information and Pfizer Pharmaceuticals Ltd. 
(China)'s performance, we collected data from the Statistical Yearbooks of Chinese Pharmaceutical Industry released by the former State Economic and Trade Commission (SETC) of China, and the market reports released by the China Southern Institute of Pharmaceutical Economics, a market research agency affiliated with SFDA. Because there are different coding systems in terms of the therapeutic categories of chemical drugs, we adopted the ATC (Anatomical Therapeutic Chemical) classification system ${ }^{2}$ to unify the categorization of data from different sources. The ATC classification system is recommended by the World Health Organization and is widely used by industrial analysts.

\subsection{The evolution path of Pfizer's business in China, 1993-2002}

Pfizer is a research-oriented global leader in the world pharmaceutical industry. Headquartered in the U.S., it has more than 150 years of history. In 2002, its global revenues from the pharmaceuticals sector were 28.3 billion US dollars, which was the top one in the industry. Broken down into the therapeutic categories, as can be seen from Fig.1, Pfizer's annual global revenues in 1994, 1996, 1998, 2000 and 2002 mainly came from (in order of revenue size): cardiovascular system, central nervous system, anti-infectives, genito urinary system, metabolism systems (mainly refer to drugs for diabetes), and musculo-skeletal system (mainly refer to drugs for arthritis). As most other top pharmaceutical companies in the world, blockbusters or leading products accounted for large proportions of total sales. Fig.2 listed seven of Pfizer's worldwide leading products and their corresponding global revenues during 1994-2002. They are: Norvasc, Zoloft, Zithromax, Diflucan, Viagra, Feldene and Sulperazon. As we will see in the following analysis, all of these worldwide market blockbusters for Pfizer were put into local production in China.

Pfizer operates in China mainly through Pfizer Pharmaceuticals Ltd, a joint venture it established with Dalian Pharmaceutical Plant in the Liaoning province of North-eastern China in 1993. Initial investment was 58 million US dollars, and Pfizer holds 67\% share of the ownership (Economist Intelligence Unit, 1997). The joint venture became fully operational in 1993. In April 1997, it became the first pharmaceutical company in China that received the Good Manufacturing

\footnotetext{
${ }^{2}$ There are 15 therapeutic categories in the ATC classification system, including (A) alimentary tract and metabolism, (B) blood and blood forming organs, (C) cardiovascular system, (D) dermatologicals, (G) genito urinary system and sex hormones, (H) systemic hormonal preparations, excl. sex hormones and insulins, $(\mathrm{J})$ anti-infectives for systemic use, (L)antineoplastic and immunomodulating agents, (M) musculo-skeletal system, (N) nervous system, (P) antiparasitic products, insecticides and repellents, (R) respiratory system, (S) sensory organs, (V) various. For each category, usually there are several sub-categories. For instance, drugs for diabetes fall into the sub-categories of class A in the ATC system, and drugs for arthritis fall into the sub-categories of class $\mathrm{M}$.
} 
Practice (GMP) certificate granted by the State Pharmaceutical Administration of China (SPAC). The joint venture produces drugs that are sold mainly in the Chinese market, with some exported via Pfizer's corporate-wide coordination of global production. To improve customer services and business coordination, in 1997, Pfizer re located its regional headquarter in Beijing ${ }^{3}$. It also set up sales offices throughout China and undertook R\&D activities in China as well. The $\mathrm{R} \& \mathrm{D}$ activities were largely limited to the clinical tests in new drug development. By 2000, Pfizer hired approximately 750 employees in China, and its sales revenues were 52.6 million US dollars. Its revenues in China also grew rapidly, increasing from 8.1 million US dollars in 1993 to 55.9 million US dollars in 2001. The average annual growth rate for Pfizer Pharmaceuticals Ltd. (China) during the period was $27.3 \%$.

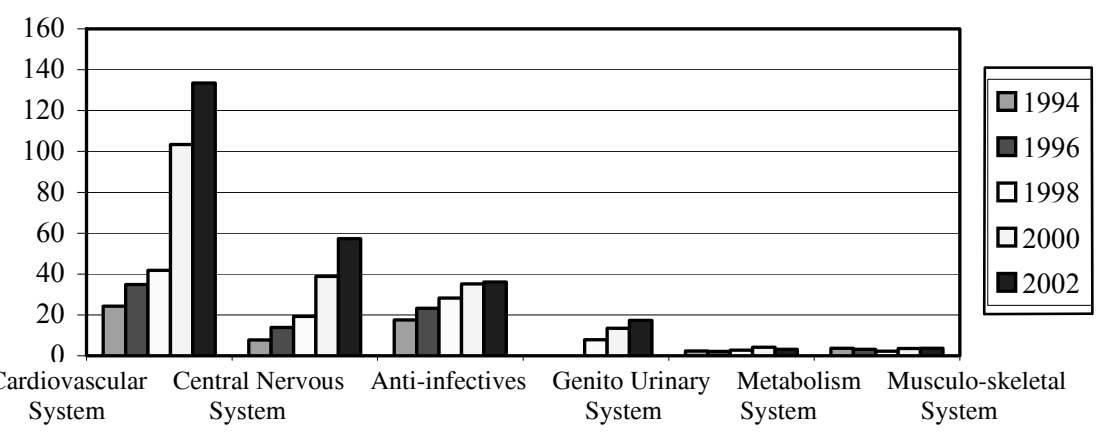

Source: Adapted from the annual reports of Pfizer Inc.(Unit: 100 million USD).

Fig. 1 Breakdown of Pfizer's global revenues by the main therapeutic categories

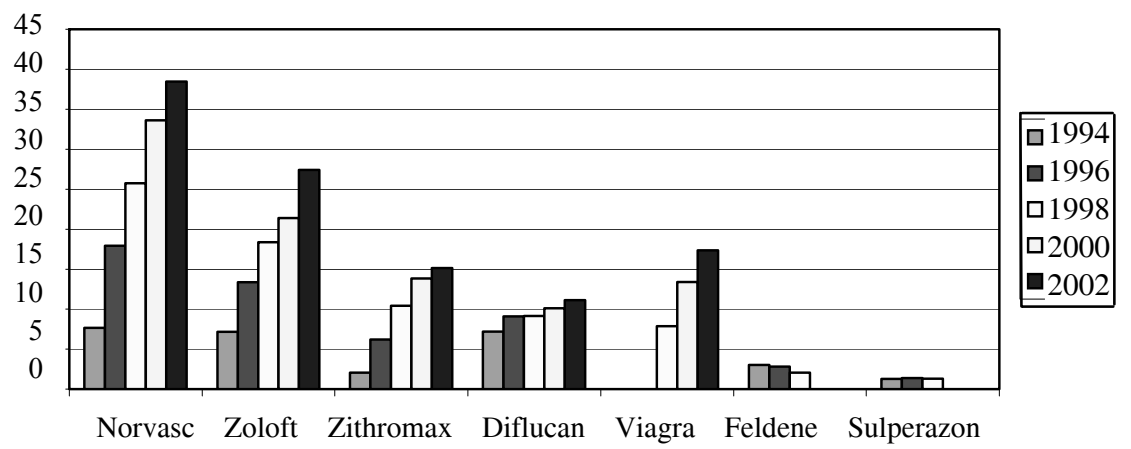

Source: Adapted from the annual reports of Pfizer Inc.(Unit: 100 million USD).

Fig. 2 Breakdown of Pfizer's global revenues by its global blockbusters

\footnotetext{
${ }^{3}$ Following the globe merger of Pfizer and Pharmacia in April 2003, Pfizer (China) relocated its regional headquarter in Shanghai.
} 
Table 1 lists the drug production licenses Pfizer obtained in China and their distribution across different therapeutic categories. For each category, we listed the name of each product brand in the category, the year of the first drug production license granted to each brand, the total number of product brands, and the total number of drug production licenses. Relatedly, we define a product family as a set of drugs that using the same brand name, which usually contain the same main ingredients but have different preparation forms or dosages. The number of drugs using the same brand name reflects the density of the product family. For instance, the main ingredient of drugs under the brand name of Zithromax is Azithromycin, but their preparation forms vary from those that suit adults (such as capsules and tablets) to those that suit children (such as suspensions). In addition, for different clinical purposes, there are pills with different dosages for Zithromax. Usually, the main driver for drug producers to launch a series of drugs under one brand name is to further differentiate their products to meet the specific needs of various patient groups (e.g. patients in different age groups) with similar diseases. As the application for drug production licenses requires considerable investment of time and money, the density of a product family reflects both the objective condition of the market demand for the product, and the subjective attention of the company paid to the corresponding market segment. Since 1993, the drugs produced by Pfizer Pharmaceuticals Ltd. (China) can be grouped into eleven product families and covered seven therapeutic categories. Among the eleven product families, eight are Pfizer's worldwide leading products, including Norvasc for cardiovascular diseases, Zoloft for central nervous system, Diflucan, Zithromax, Sulperazon for infectious diseases, Feldene for arthritis, Glucotrol for anti-diabetes, and Viagra for genitourinary conditions. Among the remaining three products, Cofrel is for respiratory diseases, and Cefobid and Doxcycline for infectious diseases.

Table 1 A List of drug licenses obtained by Pfizer pharmaceuticals Ltd. (China), 1993-2002

\begin{tabular}{llrc}
\hline Therapeutic category & $\begin{array}{l}\text { Name of product brand \& the year of } \\
\text { first drug license granted to the brand } \\
\text { in China }\end{array}$ & $\begin{array}{c}\text { No. of } \\
\text { brands }\end{array}$ & $\begin{array}{l}\text { No. of } \\
\text { licenses }\end{array}$ \\
\hline Anti-infectives & $\begin{array}{l}\text { Diflucan (1993), Zithromax (1995), } \\
\text { Sulperazon (1996), Cefobid (1996), } \\
\text { Doxycycline (1999) }\end{array}$ & 5 & 18 \\
Cardiovascular system & Norvasc (1995) & 1 & 1 \\
Respiratory system & Cofrel (1996) & 1 & 1 \\
Musculo-skeletal system & Feldene (1996) & 1 & 4 \\
Metabolism system & Glucotrol (1997) & 1 & 1 \\
Central Nerves system & Zoloft (1998) & 1 & 3 \\
Genitourinary system & Viagra (2002) & 11 & 29 \\
Sum & $\quad-$ &
\end{tabular}

Source: SFDA database for drug production licenses. 
As can be seen from Table 1, Pfizer continuously added drugs to its local production list in China and expanded their coverage of the therapeutic categories. In the order of starting years, Pfizer began local production of anti-infectives in 1993, drugs for cardiovascular system in 1995, drugs for arthritis and respiratory system both in 1996, anti-diabetes in 1997, drugs for the central nervous system in 1998 and drugs for genitourinary conditions in 2002. Diflucan, a therapy for a wide range of fungal infections, is Pfizer's first product launched for local production in China and was granted production license in 1993. Besides, Table 1 also indicates that the distribution of Pfizer's drug production licenses in China across the seven therapeutic categories is largely imbalanced. In particular, there are eighteen licenses and five brands in the anti-infectives category, which makes it an undisputable leading category among the seven, in terms of the number of product families and the average density of the product families. For the remaining six therapeutic categories, although they have one product brand each, the density of the product family using each brand differs. For instance, while there are four drug licenses for Feldene, there are only one drug license for Cofrel.

Fig.3 depicts the evolutionary path of Pfizer Pharmaceuticals Ltd.'s local production in China during 1993-2002. From Fig.3, we can examine the processes of Pfizer's product launching across the different therapeutic categories. In Fig.3, we listed the drug licenses obtained by Pfizer in each year, grouped by their brand names. The corresponding therapeutic categories of the drugs, their preparation forms and dosages (as approved by SFDA and its precursor) are also listed. Consistent with our observations from Table 1, the mapping of Pfizer's production scope evolution in Fig.3 confirms that, by the end of 2002, Pfizer had been awarded twenty-nine drug production licenses, covering eleven product brands and seven therapeutic categories.

Different from the sequential mode of MNCs' business entries into overseas markets, as discussed in Chang (1996) and Chang and Rosenzweig (1998a), Fig. 3 indicates that Pfizer's production scope evolution in China during our study period exhibits a recursive pattern. This is reflected in the fact that the distribution of Pfizer's product licenses across the different therapeutic categories and the timing of the licenses added to Pfizer's product portfolio did not follow the sequence of Pfizer's corporate strengths across its product brands and/or therapeutic categories (revealed in the relative size of their broken-down global sales as shown in Fig.1 and Fig.2). For instance, Diflucan was the first drug that was put into local production in China. But it did not belong to the category of drugs for cardiovascular systems, which was the strongest category in Pfizer's global sales. Interestingly, anti-infective drug, the therapeutic category of Diflucan, was the top category in terms of sales revenue in China's prescription drugs market. Besides, as the product scope of Pfizer in China evolved over time, 


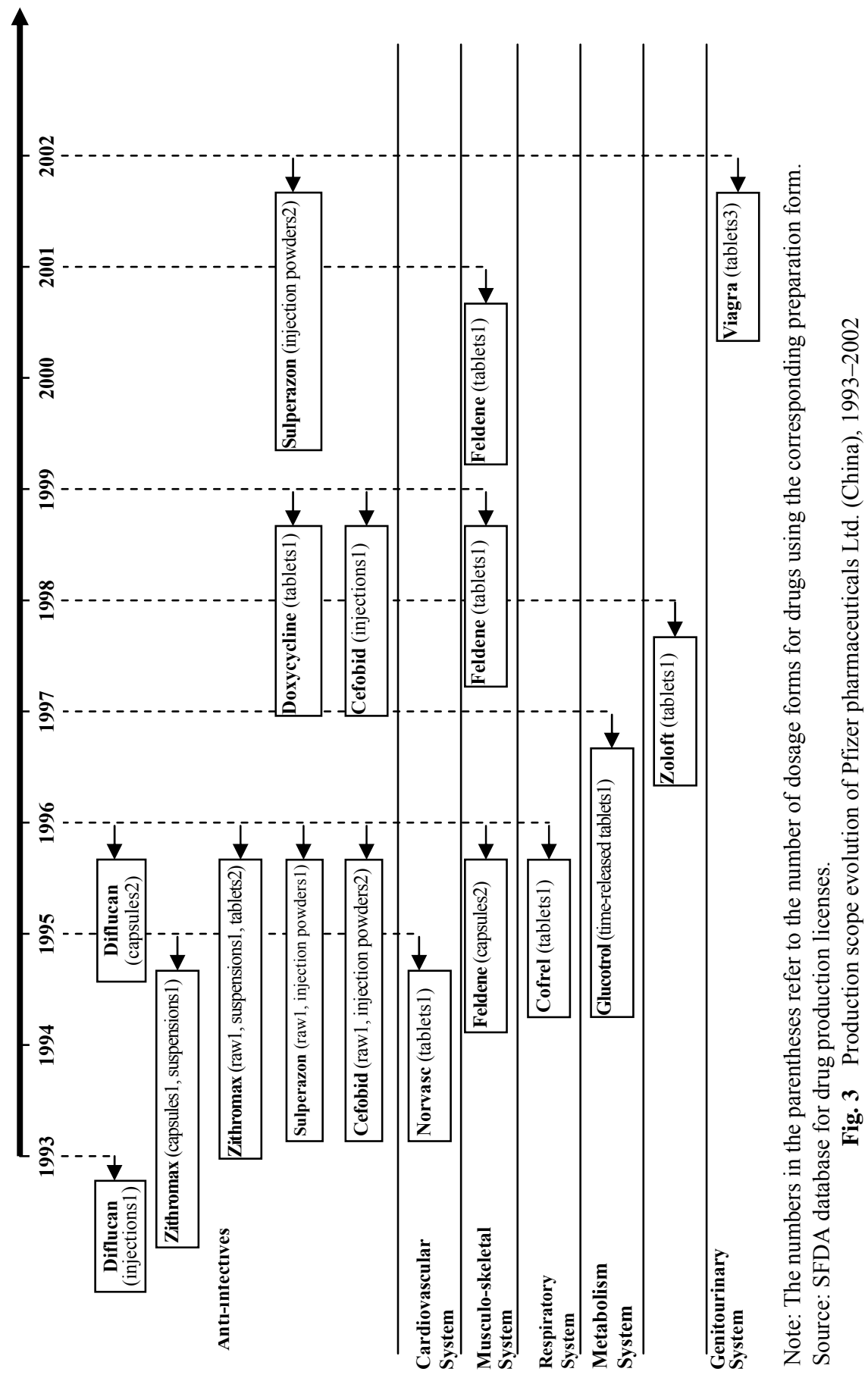


the procedures of the drugs added to each therapeutic category were quite different as well. While some therapeutic categories (e.g., anti-infectives and drugs for the musculo-skeletal system) experienced active expansion of the drug lists for local production, others (e.g., the central nerves system and the respiratory system) remained the same after obtaining its first drug license. In the category of anti-infective drugs, Pfizer obtained its first local production license for Diflucan in the preparation form of injections. It then added Zithromax in two preparation forms (i.e., capsules and suspensions) in 1995. In 1996, Pfizer started local production of anti-infective drugs bearing another two brands, Sulperazon and Cefobid. For each of the two new product families, Pfizer obtained two licenses - one for raw materials and another for injection powders. In the same year, Pfizer strengthened its existing two brands in the anti-infectives category, i.e., Diflucan and Zithromax, by obtaining new licenses for drugs with different preparation forms or dosages. In 1999, Pfizer was approved to produce yet another anti-infective drug in China, i.e., Doxcycline prepared in tablets. At the same time, it obtained one more license for the production of Cefobid in the preparation form of injections. By 2002, Pfizer added another two drugs to the local production lists They are injection powders in the Sulperazon family, but with different dosages. Except the anti-infectives, another therapeutic category Pfizer was active contains drugs for the musculo-skeletal system (in particular, drugs for arthritis). Since obtaining the first product license for Feldene in this category in 1996, Pfizer added drug licenses for different preparation forms and dosages to the product family with the same brand in 1999 and 2001 respectively. In contrast to these two therapeutic categories, Pfizer did not add any new brands or new drugs to an existing brand in the other five therapeutic categories. Based on these observations of Fig.3, we conclude that Pfizer's production scope evolution in China followed a recursive pattern and was imbalanced across the different therapeutic categories.

\section{Findings and discussion}

4.1 The dual pressures in international business operation and the impact on the business scope evolution of MNC overseas subsidiaries

As Ghoshal and Bartlett (1991) noted, MNCs can be viewed as interorganizational networks and their subsidiaries act as the nodes that link the various exchange relationships within and outside of MNCs. Through the exchange of information and resources, including those between MNC headquarter and the subsidiaries and those between the subsidiaries and their host market, MNC subsidiaries are subject to influences from other nodes in the network. The challenge brought by the 
multiple forces of network influence to the subsidiaries is the dual pressures of keeping corporate-wide integration and local responsiveness. On the one hand, due to transaction costs in the arms-length market (Hennart and Park, 1993) and MNCs' organizational coordination strength (Kogut and Zander, 1993), there is incentive for subsidiaries to leverage corporate strength and for MNCs to keep global integration (Yip, 1995). On the other hand, resource dependence theory suggests that, as subsidiaries operating in host country market, they have to pay attention to local stakeholders, such as customers, suppliers, competitors, and policy-makers, so that they can survive and grow. For multinational pharmaceutical firms, pressures for corporate-wide integration are strong because, coordinated product launching and marketing activities across different parts of the world can considerably reduce the unit cost associated with the increasingly heavy investment on new drug development, prolong the product life-cycle of new products so that the profits of new drugs can be fully captured. In the Pfizer case, efforts for global integration are mainly reflected in the introduction of Pfizer's worldwide blockbusters to its local production in China. Meanwhile, pressures for local responsiveness also exist and become stronger when MNC subsidiaries try to outperform their local competitors and achieve superior performance in the local market. To obtain competitive advantage, they usually need to acquire thorough understanding of the local customer needs, and keep adaptive by tailoring their products and services to meet the local needs. As reflected in the case of Pfizer Pharmaceuticals Ltd. (China), it tried to respond to the Chinese market by launching new products and strengthening the product families in those therapeutic categories that correspond to the areas with higher demand in the prescription drug market of China.

Table 2 indicates the distribution of Pfizer's production in China across the different therapeutic categories. Column A lists the proportion of Pfizer's aggregated number of drug licenses obtained in China during 1993-2002. It shows that about two-thirds of the drug licenses Pfizer obtained in China are in the anti-infectives category $(62.07 \%$ ), with another $13.79 \%$ and $10.34 \%$ falling into the musculo-skeletal system and the genitourinary system respectively. Column B lists the proportion of product families in each category. It also indicates that anti-infective drug is the leading category, which contained almost half of the product families Pfizer produced in China (45.46\%). 
Table 2 Comparison of the drug licenses obtained by Pfizer pharmaceuticals Ltd. (China) across different therapeutic categories with Pfizer's global revenue and the sales of prescription drugs in China

\begin{tabular}{|c|c|c|c|c|}
\hline $\begin{array}{l}\text { Therapeutic } \\
\text { categories }\end{array}$ & $\begin{array}{l}\text { (A) } \\
\text { Aggregated } \\
\text { number of } \\
\text { drug licenses } \\
\text { obtained by } \\
\text { Pfizer in } \\
\text { China during } \\
1993-2002 \\
(\%)\end{array}$ & $\begin{array}{l}(\mathrm{B}) \\
\text { Aggregated } \\
\text { number of } \\
\text { product } \\
\text { families } \\
\text { produced by } \\
\text { Pfizer in } \\
\text { China }(\%)\end{array}$ & $\begin{array}{l}(\mathrm{C}) \\
\text { Aggregated } \\
\text { global } \\
\text { revenue of } \\
\text { Pfizer Inc. } \\
\text { during } \\
\text { 1994-2002 } \\
(\%)\end{array}$ & $\begin{array}{l}\text { (D) } \\
\text { Aggregated } \\
\text { sales of the } \\
\text { prescription } \\
\text { drugs in } \\
\text { China } \\
\text { during } \\
2001-2002 \\
(\%)\end{array}$ \\
\hline Anti-infectives & 62.07 & 45.46 & 18.60 & 27.09 \\
\hline $\begin{array}{l}\text { Cardiovascular } \\
\text { system }\end{array}$ & 3.45 & 9.09 & 43.72 & 15.17 \\
\hline $\begin{array}{l}\text { Musculo-skeletal } \\
\text { system }\end{array}$ & 13.79 & 9.09 & 2.04 & 2.31 \\
\hline $\begin{array}{l}\text { Metabolism } \\
\text { system }\end{array}$ & 3.45 & 9.09 & 2.23 & 13.02 \\
\hline $\begin{array}{l}\text { Central nerves } \\
\text { system (CNS) }\end{array}$ & 3.45 & 9.09 & 17.45 & 5.88 \\
\hline $\begin{array}{l}\text { Genitourinary } \\
\text { system }\end{array}$ & 10.34 & 9.09 & 4.59 & 2.45 \\
\hline Other & 3.45 & 9.09 & 11.37 & 34.08 \\
\hline Sum & 100.00 & 100.00 & 100.00 & 100.00 \\
\hline
\end{tabular}

Source: SFDA database for drug production licenses, monitoring reports of drugs prescribed by hospitals in China released by China Southern Institute of Pharmaceutical Economics, and the annual reports of Pfizer Inc.

Table 2 also lists information on the distribution of Pfizer's worldwide revenue across different therapeutic categories in column $\mathrm{C}$, and the distribution of sales across the same categories in the Chinese prescription drug market in column D. Our purpose is to use these data to analyze the integration-responsiveness dual pressures faced by Pfizer in its operation in China. In column $\mathrm{C}$, we use the percentage of the corporate global revenue contributed by each therapeutic category as the indicator of its strength in corporate product portfolio ${ }^{4}$. Those therapeutic categories with larger share in Pfizer's corporate global sales are regarded as having greater strengths in terms of marketing and/or R\&D capabilities, and presenting stronger incentives for Pfizer's subsidiary in China to

\footnotetext{
${ }^{4}$ Based on data availability, we were able to collect detailed information on the annual sales of Pfizer, inc. for our study period except 1993. The percentage of sales for each category in the Pfizer's total revenue, as reported in column $\mathrm{C}$ of table 2, is the aggregated annual sales for each therapeutic category across the nine years (1994-2002) divided by the aggregated global sales of all the therapeutic categories of Pfizer over the same time period.
} 
leverage on the corporate strength and launch more products in the categories. As shown in column $\mathrm{C}$, the three leading therapeutic categories in Pfizer's aggregated global revenue during 1994-2002 are cardiovascular system (43.72\%), anti-infectives $(18.60 \%)$, and central nerves system (17.45\%). To measure the pressure of keeping responsiveness to the local market conditions, and in particular, the local market demand for Pfizer in China, we collected data on the annual sales of prescription drugs in China across the different therapeutic categories during 2001-2002. While the market demand for pharmaceutical firms that can be divided into two parts, i.e. those for prescription drugs prescribed via hospitals et al., and those for the OTC (over-the-counter) drugs, data collected from Pfizer's annual reports during 1994-2002 suggests that over 95\% of Pfizer's global revenue came from prescription drugs, suggesting Pfizer mainly competes in the segment of prescription drugs. Hence the market demand of prescription drugs is what matters for Pfizer. Those therapeutic categories that having larger share of sales in China's prescription drug market are regarded as having stronger market demand and bringing greater pressures for Pfizer to launch more products in the corresponding categories. Column D reports the proportion of the different therapeutic categories in the aggregated sales of prescription drugs in China during 2001-2002 $2^{5}$. The total sales revenue of the drugs prescribed across the more than 360 sample hospitals monitored by China Southern Institute of Pharmaceutical Economics (CSIPE) in 2001 was 10.97 billion RMB yuan, and the amount increased to 12.94 billion yuan in 2002 . Column D shows that, in the aggregated sales of prescription drugs during the two years, the top three therapeutic categories are anti-infectives $(27.09 \%)$, cardiovascular system (15.17\%), and metabolism system(13.02\%).

We further conducted correlation analysis to measure the interdependence among the data listed in the different columns in Table 2. The magnitude of the coefficient indicates the strength of interdependence between two sets of data. Greater value of a correlation coefficient means that more variances of a dataset can be explained by those in another. Hence, when a correlation coefficient

\footnotetext{
${ }^{5}$ The data came from the annual market monitoring reports of prescription drugs released by China Southern Institute of Pharmaceutical Economics (CSIPE) in 2001 and 2002. It contained information on the breakdown of sales by therapeutic categories of drugs prescribed in more than 360 monitored sample hospitals across 16 major provincial capital cities in China. The 16 cities are Beijing, Tianjin, Shanghai, Hangzhou, Guangzhou, Nanjing, Wuhan, Haerbin, Xian, Shijiazhuang, Shenyang, Jinan, Zhengzhou, Changsha, Chongqing, Chengdu. Unfortunately, data on prescription drugs in China did not contain detailed information on each therapeutic category prior to 2001. We consulted industrial analysts at the CSIPE, and were confirmed that the ranking order of demands across the different therapeutic categories of prescription drugs in China was stable during our study period (1993-2002). Hence, we regard the patterns revealed in the data of the two years (2001 and 2002) representative of those in the years (1993-2002).
} 
equals zero, it indicates that the two data sets are independent of each other. Using the Pearson correlation coefficient analysis ${ }^{6}$, we first computed the correlation coefficients between the distribution of Pfizer's drug licenses in China by therapeutic categories during 1993-2002 (column A) and the distribution of Pfizer's global revenue by therapeutic categories during 1994-2002 (column C), and that between column A and the distribution of sales of prescription drugs in China by therapeutic categories during 2001-2002 (column D) ${ }^{7}$. We then duplicated the analysis by replacing column A by the distribution of Pfizer's product families in China by therapeutic categories in China during 1993-2002 (column B). Our analysis supports the following two findings.

First, we found that there existed considerable discrepancies between the dual pressures faced by Pfizer in its operation in China. This is reflected in the fact that the correlation coefficient between columns C and D is $0.446(p<0.38$, two-tailed test), which was not statistically significant ${ }^{8}$. In other words, the positive correlation coefficient between columns $\mathrm{C}$ and $\mathrm{D}$ was not significantly different from zero. Hence, we conclude that there are little interdependences between the dual pressures faced by Pfizer, or, put it different, there are considerable discrepancies between them. Supposing the distribution of Pfizer's global revenue across the different therapeutic categories approximately reflects what Pfizer pays attention to and what it is good at in the major global markets, i.e., North America and Europe, our speculation on the causes of the discrepancies is that the disease spectrum, consumer's drug consumption level and consumption habits, and the regulative policies of drug production and new drug application in China are quite different from what Pfizer used to face in its major global markets. The case of anti-infective drugs lends some support to our speculation. As China is a developing country, many regions still have poor medical conditions and health care infrastructure. Infective diseases usually have higher occurrence rate than other diseases. Besides, because many infective diseases require immediate treatment and usually have had cheaper generic drugs as effective therapies, Chinese patients spend far more money on the anti-infective drugs, as compared with other drugs, than their Western counterparts. Another

$\overline{6}$ Pearson correlation coefficient for data sets $\left\{X_{i}\right\}$ and $\left\{Y_{i}\right\}$ is calculated as:

$\rho_{X, Y}=\frac{\operatorname{cov}(X, Y)}{\sigma_{X} \sigma_{Y}}$, where: $\operatorname{COV}(X, Y)=\frac{1}{n} \sum_{i}\left[\left(X_{i}-\mu_{x}\right)\left(Y_{i}-\mu_{y}\right)\right] \sigma_{x}=\sqrt{\frac{1}{n} \sum_{j}\left(X_{j}-\mu_{x}\right)^{2}}$ $\sigma_{y}=\sqrt{\frac{1}{n} \sum_{j}\left(Y_{j}-\mu_{y}\right)^{2}}$

${ }^{7}$ We did not include the "Other" item into the calculation of the correlation coefficient, because those that counted into the "other" item are slightly different across the different columns (reptesenting different report systems). 
example that illustrates the difference between the demand of Chinese consumers and that of western consumers is the drugs for CNS. Pfizer's global blockbuster product in this therapeutic category is Zoloft, which was an effective therapy for many different types of depression and anxiety. But due to the lack of strong demand in the therapeutic category, which is caused either by the ignorance of Chinese patients of the disease or their purposeful shun-away from it, Zoloft did not contribute to Pfizer's sales in China as much as it did to the corporate globe revenue. As a manifest, and as we can see from Fig.3, after Pfizer obtained its first drug license for Zoloft in China in 1998, there has been no new drug licenses added to the therapeutic category ever since then.

Second, we also found from the correlation analysis of data listed in Table 2 that, although conflicting dual pressures of keeping corporate global integration and keeping local responsiveness co-exist, and both are likely to exert influences on Pfizer's strategic choices, the evolutionary path of the production scope of Pfizer Pharmaceuticals Ltd. (China) corresponded more closely to the local market conditions in China. This is supported by our correlation analysis, in which we found that the correlation coefficient between columns A (the distribution of Pfizer's drug licenses in China by therapeutic categories during 1993-2002) and C (the distribution of Pfizer's global revenue by therapeutic categories during 1994-2002) is 0.012 ( $p<0.98$, two-tailed test), which was not statistically significant, and that between columns A and D (the distribution of sales of prescription drugs in China by therapeutic categories during 2001-2002) is 0.737 ( $p<0.10$, two-tailed test), which was significant. Similarly, when we replaced column A by column B (the distribution of Pfizer's product families in China by therapeutic categories in China during 1993-2002), and used the latter to measure the distribution of Pfizer's production scope in China across different therapeutic areas, the results remained the same. Specifically, we found that the correlation coefficient between columns B and C is 0.117 ( $p<0.83$, two-tailed test), which was not significant, and that between columns B and D is 0.827 $(p<0.04$, two-tailed test), which was highly significant. The results suggest that, in facing the dual pressures imposed on Pfizer from both the corporate side and the host market side, Pfizer's production scope distribution exhibited much stronger and positive correspondence to the local demand conditions in China. Figures 4(a) and 4(b) further depict the comparisons between Pfizer's production scope evolution in China and the dual pressures it has to face, i.e., keeping alignment with its corporate strength on the one hand, and with local market conditions on the other. From the two figures, we can see that, no matter we use the distribution of drug licenses or product families as the proxy for Pfizer's production scope distribution across the different therapeutic categories, it corresponds more closely to the distribution of the local demand conditions in China. 


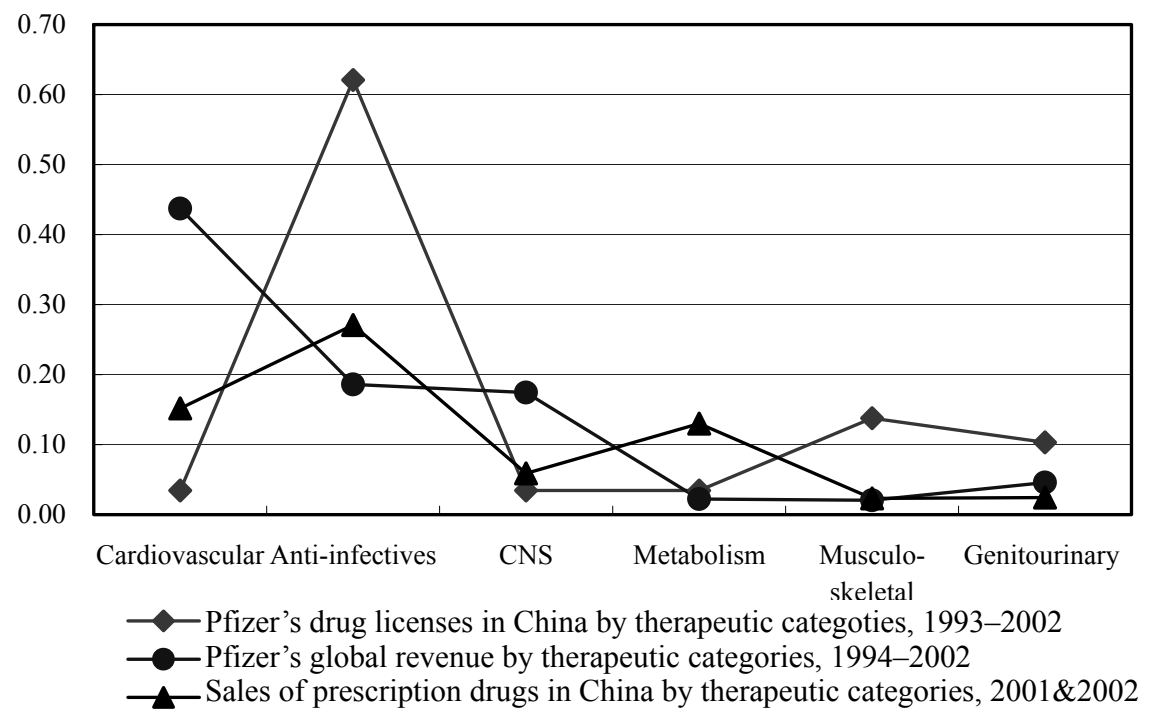

Fig. 4(a) Comparison of the distribution of Pfizer's drug licenses in China with its corporate global revenue composition and the local market conditions

Source: SFDA database for drug production licenses, monitoring reports of drugs prescribed by hospitals in China released by China Southern Institute of Pharmaceutical Economics, and the annual reports of Pfizer Inc.

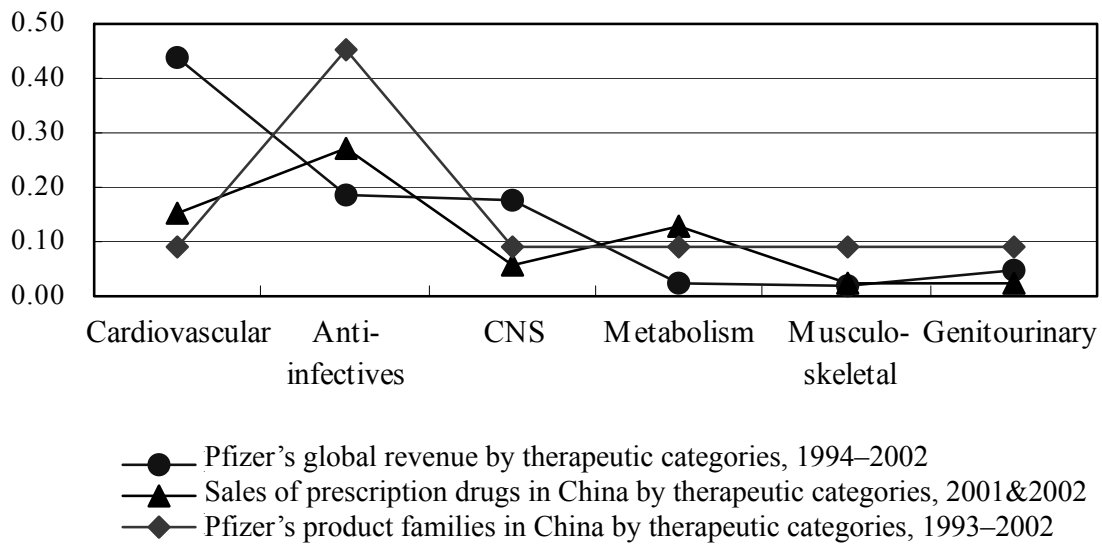

Fig. 4(b) Comparison of the distribution of Pfizer's product families in China with its corporate global revenue composition and the local market conditions

Source: SFDA database for drug production licenses, monitoring reports of drugs prescribed by hospitals in China released by China Southern Institute of Pharmaceutical Economics, and the annual reports of Pfizer Inc. 
Noteworthily, the above finding is based on our case study of Pfizer Pharmaceuticals Ltd. (China). Like other case studies, the finding holds true only when the assumptions that are associated with the specific contextual factors of the case are met. The two implicit assumptions underlying our finding of Pfizer(China), i.e., MNC subsidiary exhibits stronger responses to local market conditions than to the internal alignment within the corporate, are that (1) there is large discrepancy between the dual pressures faced by the MNC and the subsidiary, and (2) the host country market of the subsidiary is strategically important to the MNC (e.g., having higher growth rate in market demand, or contributing as a major source of profits).

4.2 Strategic choices of MNCs in expanding overseas business and the generic strategic parameters in their adjustment of subsidiary development path

As we can see from the Pfizer case, MNCs usually have to face more complicated situations in decision-making than those companies that compete in their home market only. Fig.5 illustrates some of the critical decision points for MNCs in making strategic choices for their overseas business operations. The first set of choices is related to the strategic positioning of the MNCs with regard to their overseas business, among which a very important choice is the motivation of MNC's entry into the overseas market, and related, the strategic roles of the overseas subsidiaries. Extant literature suggested that the major types of the motivation for MNCs' international business activities include market-seeking, resource-seeking and efficiency-seeking (Dunning, 1988). Using survey data and clustering analysis, Zhao(2002) also found that the strategic roles of MNC subsidiaries in China can be classified into four categories, namely market-expansion, production-base, risk-aversion, and knowledge-seeking. The second set of choices is more closely related to the implementation of MNCs strategies in their overseas business development. One aspect of the implementation choices is related to the initial entry mode, which further includes the choices of the ownership mode (e.g. adopting greenfield entry or acquisition) and the locational choice of the investment. Another aspect of strategic implementation is related to the subsequent development of the MNCs in the overseas market (e.g. making choices on the content of business operations and the processes of business development in the host country). The two sets of choices are not independent to each other. Often, choices related to MNCs strategic positioning in the overseas market will influence their choices on strategic implementation and vice versa. For instance, for those MNC subsidiaries that position themselves as taking the resource-seeking role, their locational choice will direct to those areas that have abundant resources (e.g. the middle and western regions of China), but for those that are market-seeking, they 
often seek coastal regions in Eastern China that are more heavily populated and have higher average consumption level.

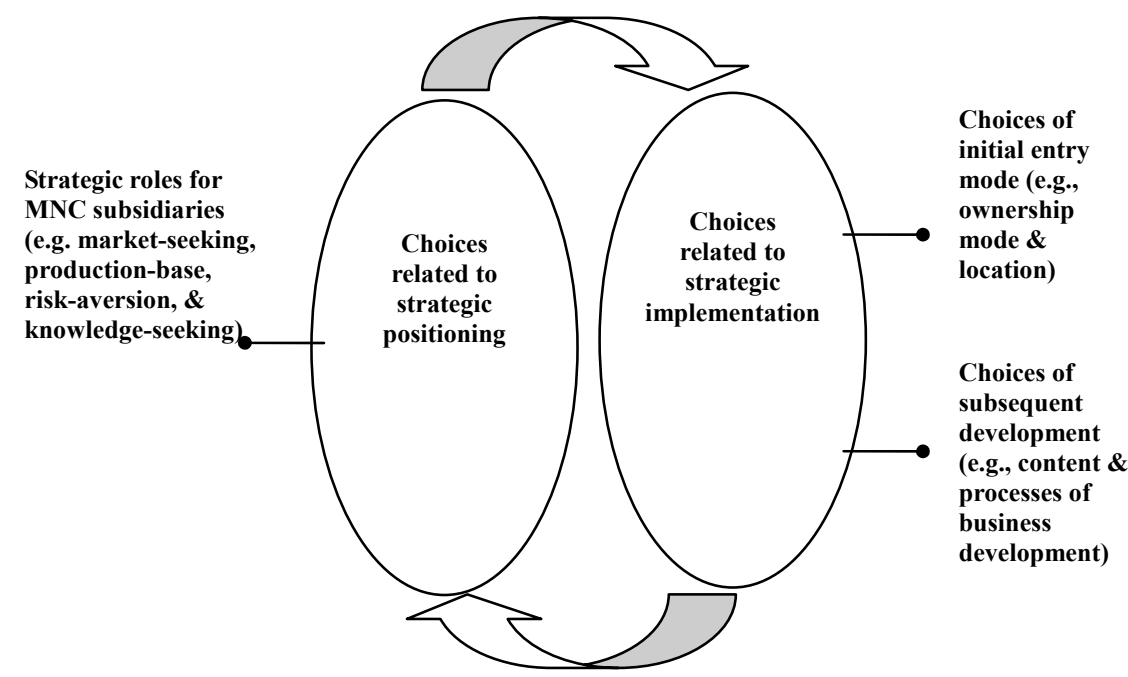

Fig. 5 Strategic choices of firms in overseas business operations

Our case study of Pfizer's production scope evolution in China during 1993 to 2002 also illustrates how the different components of the decision-making system, as illustrate in Fig. 5, are linked together when MNCs cope with the challenges of doing business in overseas markets. In terms of the strategic positioning, Pfizer Pharmaceuticals Ltd. (China) exhibited strong market-seeking orientation, which becomes more evident when it is compared with other multinational pharmaceutical companies (e.g., Glaxo and Merck) that entered China in the mid-1990s as well. While those other MNC pharmaceutical companies mainly use their subsidiaries in China as a hub for extending the product life cycle of their blockbusters that facing imminent patent expiration. Pfizer took local market demand into the consideration of its product launching strategy in China. One example is Viagra. Pfizer obtained local production license for Viagra in China in 2002, shortly after Pfizer got new drug approval for Viagra from the US FDA in March 1998. The rationale for Pfizer's product launching strategy of Viagra in China suggests that the huge population base and the potential demand for Viagra in China provided strong incentive for Pfizer to launch products based on their potentiality of creating market success. In terms of strategic implementation, due to the regulative policies of Chinese government on foreign investments in the pharmaceutical industry, Pfizer's initial choice of ownership mode was basically constrained to setting up joint ventures with local 
partner. However, in the subsequent business development of the joint venture, Pfizer played a key role in making strategic decisions on product portfolio management and other important aspects of the daily operation of the JV. Our case study focused on mapping the production scope evolution of Pfizer in China during 1993-2002. The most salient characteristic of Pfizer's evolutionary path in China is the recursive pattern in the process of its business scope development. From our viewpoint, the recursive pattern is the direct response of Pfizer to the uncertainties it had to face when it entered into an unfamiliar market. It is also a revelation of the bounded rationality of the decision-makers. However, by experimenting and adjusting its product launching strategies along the recursive path, Pfizer found the balance between leveraging its global strength and, moreover, responding to the local market conditions. Although the development path of Pfizer is highly idiosyncratic, we found that some of the parameters are common to other companies as well. More specifically, we find that there are two types of parameters that determine the development path of a company. One type is the content parameters that are concerned with the adjustment of the content of the business operation. The other type is the process parameters that consist of the elementary processes of changes in companies' business operations.

Taking the scope of business operation as a distribution of products/services across the different categories or lines of businesses, the three content parameters that define the main characteristics of the distribution are breadth, depth and evenness. Breadth refers to the span of coverage of the business scope, measured by the number of lines of businesses or product categories. In the Pfizer case, its local production licenses covered seven therapeutic categories. Both expansion and extraction of the product/service offerings can lead to the change in the breadth of firm's business scope. The changes often take considerable time and efforts. For instance, expanding into a new category not only involves additional efforts in applying for new production license or investment in production facilities, but also involves significant changes related with competition conditions, personnel allocation, supplier management, marketing strategy and distributional channels. Density of business scope refers to how many products or services each line of business has. In the Pfizer case, altogether there are eleven product brands and twenty-nine production licenses, and they are dispersed in the seven therapeutic categories. The density of products in each therapeutic category provides useful information, including focal firm's commitment to the line of business, market demand and competition conditions in the category. Evenness of product distribution is closely related with the density of each category. It reflects the focus of firms' production scope. In the Pfizer case, its production scope is not evenly distributed across the seven categories. The category of infectious diseases leads in the density by five brands and seventeen licenses, while the other six categories have one brand each and 
one to four licenses.

The processes of business scope evolution can also be described by several process parameters, which represent the elementary change processes. Based on our observation of Pfizer's production scope change during 1993-2002, we confirmed that, similar to what Siggelkow (2002) found in his case studies of American firms, there are five process parameters, or elementary change processes, underlying firm's business scope evolution. They are: patching, thickening, coasting, trimming and eliminating. Patching refers to the expansion into a new line of business and adding products/services to the new category. Thickening refers to the reinforcement of an existing line of business by increasing the density of products/services in the category. Coasting refers to retaining the status quo in firm's business scope in a given period. Trimming refers to the reduction of products and services in an existing cline of business, and consequently, the decrease of the density of products/services in the category. Eliminating refers to the exit from an existing line of business and the deletion of the category from firm's business scope. While patching and eliminating represent the more dramatic changes, thickening, coasting and trimming are the routines underlying organizational evolution. The process parameters, as reflected in the five elementary change processes, provide the grammar of a language in describing firm's evolutionary paths towards different configurations of business scopes and the transitions between the configurations. In the Pfizer's case, as we illustrated in Fig.3, patching took the form of launching products for local production in a new therapeutic category. Thickening took several forms, including adding new brands of products in a therapeutic category that it has already had local production, adding new preparation forms (such as adding chewing tablets to capsules), and adding dosage forms (such as adding $0.25 \mathrm{mg}$ dosage tablets to $0.10 \mathrm{mg}$ dosage tablets). Coasting occurred to many therapeutic categories, such as drugs for the metabolism system, which do not have other products launched after the anti-diabetes drug, Glucotrol, was launched in China in 1997. Trimming and eliminating were not observed, mainly because the subsidiary still has a very short history and is at the stage of growing. Over time, trimming and eliminating might happen, for instance, when firms exit from certain therapeutic categories or, to a minor degree, reduce product licenses in the categories over time when some of the drug production licenses expire.

Combining the adjustment of the content and process parameters regarding to their business scopes, firms can strike a balance between maintaining local responsiveness and trying to leverage corporate strength. In the Pfizer case, we find that there are several features in its production scope evolution over the ten-year study period. First, at the early stage of its operation in China, Pfizer frequently launched new products into different therapeutic categories, and quickly achieved reasonably wide product breadth. In other words, patching was 
frequently used in Pfizer's initial production scope development. In addition to the anti-infectious drugs, which became the area that Pfizer launched most of its products in China, Pfizer also obtained product licenses in five other therapeutic categories within the fives years. The initial wide breadth of its product scope allowed Pfizer to "try the water" in different market segments, and accumulate knowledge of the local market conditions (e.g., demand, competition, distribution channels et. al.) through its own "trials-and-errors" experiences. Second, as Pfizer's experiences with the market in China accumulated over time, it gradually differentiated the product densities across the different therapeutic categories by selectively thickening some of the categories. Among the seven therapeutic categories, Pfizer only thickened its product offerings in three. The three therapeutic categories are those either having strong market demand (such as the anti-infectious drugs) or, in which Pfizer possessed unique competitive advantage in the global market (such as the drugs for genitor-urinary system, where Pfizer obtained patent protection for Viagra). The rest four categories remained more or less the same after Pfizer's first product launches. As a result of the selective thickening processes, the unevenness across Pfizer's different therapeutic categories enlarged. These processes allowed Pfizer to prioritize its resource allocation, and focus on its expansion in some of the areas that it can more easily establish its competitive advantage.

\section{Concluding remarks}

With the fast growth of the emerging markets, they are now playing an important role in the global economy. In this study, we try to analyze if the MNC subsidiaries located in the emerging markets face similar challenges as those located in the developed countries, and whether they follow the similar patterns in their development. Our findings, based on the case study of Pfizer Pharmaceuticals Ltd. (China) and its production scope evolution in China during 1993-2002, showed that, similar to what was found in the prior research (Prahalad and Doz, 1987; Bartlett and Ghoshal, 1989), MNC subsidiaries in China also have to face the dual pressures of keeping global integration and local responsiveness. Moreover, we found that, when there are large discrepancies between the two, the development paths of the subsidiaries are likely to exhibit a recursive pattern, instead of the sequential mode as suggested in the extant literature (Chang et. al., 1995, 1998a, 1998b). The recursive pattern of subsidiary development reflects the constraint of bounded rationality on the decision-makers. It also reflects that companies could obtain deeper understanding of the unfamiliar overseas market by experimenting with the adjustment of the strategic parameters pertaining to the content and processes of their development paths. The 
trials-and-errors learning processes can help companies strike a balance between the dual pressures they have to face.

Our findings also have practical implications for MNC managers, and for Chinese firms that are at the beginning stage of internationalization. For MNCs setting up subsidiaries in the overseas market, one of the rationales is that, by setting up subsidiaries, MNCs can reduce the transaction costs associated with using the arms-length market (Coarse, 1937). In addition, from the viewpoint of creating value, organizations are often more effective and efficient in intra-firm knowledge accumulation, knowledge transfer and knowledge re-combination (Kogut and Zander, 1993). Hence, MNC subsidiaries will have the incentive to leverage its corporate strength (Yip, 1995). On the other hand, the resource-dependence theory suggests that, located in the overseas markets, MNC subsidiaries also inevitably have exchange relationships with the local stakeholders (e.g., customers, employers, et. al.). These exchange relationships bring the subsidiaries pressures of keeping responsiveness to the local market conditions. Hence the dual pressures present a fundamental challenge for MNC subsidiaries, which is not just unique to Pfizer Pharmaceuticals Ltd. in China. For Chinese firms that are beginning their internationalization, compared with those MNCs headquartered in the U.S., Western Europe or Japan, their internationalization processes exhibited some different characteristics. In particular, as we observed from some of the early-movers (such as Haier and TCL), there are more firms going global not for leveraging their existing competences, but for seeking strategic assets and building competences (Kang and $\mathrm{Ke}, 2002)$. One important implication of our study to the Chinese firms is that, no matter what the initial goal is for them to go global, their success in the overseas market depends alot on the strategic implementation as well. As we found from the Pfizer case, there are several aspects that warrant more attentions from managers in their strategic implementation during the internationalization processes. First, when there are large differences between the home country and host country conditions, managers need to, in particular, pay attention to the local market conditions, and allow for a period of time for exploration. The exploration takes time because some of the local knowledge can only be acquired by practising or doing. A major risk facing firms is the liability of falling into the "competence trap", i.e., to replicate what the companies were good at in their home markets without adaptation to the local market. On the other hand, this does not mean that the companies need to "reinvent the wheels". The implication is that the companies need to be patient and gradually find out or develop the business areas that can leverage their corporate strengths and meet a major part of the local demand. While in the Pfizer case we discussed how Pfizer managed to keep local responsiveness without sacrificing global integration. Haier provides another example. When the Chinese home electronics giant entered the 
U.S. market in 1999, it did not start with producing and selling the wide-screen TVs or home entertainment centers, which were its best-sellers in China. Instead, it started by selling the compact refrigerators that suit the dormitories of college students. By finding a niche in the local market, Haier's U.S. subsidiary was able to survive. And over the time, it gradually built distribution channels via large super-market retailers and expanded its product offerings. Second, when facing unfamiliar overseas markets with considerable cultural and institutional distances (Hofstede, 1980; Xu and Shenkar, 2002) to the home country, managers are likely to be constrained by the bounded rationality in their decision-making. Hence, it is important for them to allow for flexibility in the strategic implementation processes that eventually lead to the achievement of their goals. One effective way to keep their subsidiaries flexible, as we observed from Pfizer's production scope evolution in China, is to adjust the content and process parameters of the development path of the subsidiaries' business scopes, and try to find the fit between subsidiaries' development path, MNC corporate-wide strengths and the local market conditions.

Our study also has several limitations. Further investigations in the following areas will enhance our understanding of the growth strategies of MNC subsidiaries in the overseas markets. The first limitation is related to our research method. We adopted a single case approach with a longitudinal design. Like other case studies (Eisenhardt, 1989), the method suits the purpose of finding stylized patterns or theorizing based on empirical observations, but not for testing the patterns that are found. Hence, although we believe our findings based on the Pfizer case is not unique to the case, its generalization needs to be tested with large sample data. Second, our study only focused on one aspect of firms' business scope evolution, namely the production scope evolution. Although production activities are closely related with other value chain activities (such as personnel allocation, marketing and distribution channel management et. al.), we admit that if we can get information on other aspects and pool the information together, we can get an more complete and accurate picture of firms' business operation. In that sense, our study complements prior research that focused on examining other different aspects of MNCs' value chain activities, e.g., Xue et. al. $(1999,2002,2002)$ 's work on the R\&D activities of MNCs in China. Besides, our analysis of Pfizer's production scope evolution is based on the drug licenses it obtained via SFDA or its precursors in China. Due to the restriction on our access to the "business secrets", we were not able to obtain more detailed information from Pfizer Pharmaceuticals Ltd. (China) on its sales revenue for each drug or drugs belonging to each therapeutic category. Future studies could try to get more access. Undoubtedly, the sales data will provide additional information and will help us make better assessment of Pfizer's strategy, e.g. whether the distribution of its sales corresponds more closely to the demand of 
the local market or to the distribution of its global sales aggregated at the corporate level. Finally, we identified several parameters that can adjust the content and evolutionary process of firms' business scope, and we found different combination of the parameters reflects firm's strategy. But we did not examine whether the strategic decisions are made at corporate level or at subsidiary level. Future studies can explore deeper into the managerial decision-making processes, and examine the factors that influence managers' strategic choices of firm's growth path of overseas businesses.

Acknowledgements The authors would like to thank Professor Julian Birkinshaw at the London Business School for his insightful comments on an earlier draft of this paper. We are also grateful to the anonymous reviewers of the Management World and the Frontiers of Business Research in China for their helpful feedbacks to our manuscript. Besides, the editorial assistance of Ms. Fei Liang is greatly appreciated.

\section{References}

Barkema H, Vermeulen $\mathrm{F}(1998)$. International expansion through start-up or acquisition: A learning perspective. Academy of Management Journal, 41(1): 7-26

Bartlett C, Ghoshal S(1989). Managing across borders: The transnational solution. Boston: Harvard Business School Press

Birkinshaw J(1996). How multinational subsidiary mandates are gained and lost? Journal of International Business Studies, 27: 467-495

Birkinshaw J, Hood N(1998). Multinational subsidiary evolution: Capability and charter change in foreign-owned subsidiary companies. Academy of Management Review, 23(4): 773-795

Chang Sea-Jin (1995). International expansion strategy of Japanese firms: Capability building through sequential entry. Academy of Management Journal, 38(2): 383-407

Chang Sea-Jin, Rosenzweig P M(1998a). Industry and regional patterns in sequential foreign market entry. Journal of Management Studies, 35(6): 797-822

Chang Sea-Jin, Rosenzweig P M(1998b). Functional and line of business evolution processes in MNC subsidiaries-Sony in the USA, 1972-95. In Julian Birkinshaw and Neil Hood (eds.), Multinational Corporate Evolution and Subsidiary Development. Macmillan. Chapter 12, 299-332

Coarse R(1937). The nature of the firm. Economica, (4): 386-405

Delios A, Henisz W J(2000). Japanese firms' investment strategies in emerging economies. Academy of Management Journal, 43(3): 305-323

Delios A, Henisz W J(2003). Policy uncertainty and the sequence of entry by Japanese firms, 1980-1998. Journal of International Business Studies, 34(3): 227-241

Dunning J H(1988). The eclectic paradigm of international production: A restatement and some possible extensions. Journal of International Business Studies, 19(1): 1-30.

Dunning J H(2002). Theories and Paradigms of International Business Activities: The Selected Essays of John H. Dunning. Vol. 1, Edward Elgar

Eisenhardt K.M(1989). Building theory from case study research. Academy of Management Review, 14: 532-550 
Economist Intelligence Unit (EIU)(1997). Multinational Companies in China: Winners and Losers. London, UK

Ghoshal S, Bartlett C A(1991). The multinational corporation as an interorganizational network. Academy of Management Review, 15(4): 603-625

Globerman S, Shapiro D (2003). Governance infrastructure and US foreign direct investment. Journal of International Business Studies, 34(1): 19-39

Hannart J F, Park Y(1993). Greenfields vs. acqusition: The strategy of Japanese investors in the United States. Management Science, 39: 1054-1070

Henisz W J, Andrew D(2001). Uncertainty, imitation, and plant location: Japanese multinational corporations, 1990-1996. Administrative Science Quarterly, 46: 443-475

Hofstede G(1980). Culture's Consequences. Thousand Oaks, CA: Sage

Jiang Xiaojuan(2002). Transborder investment, market structure and competitive behavior of foreign invested companies. Economic Study, (9)

Jiang Xiaojuan, Feng Yuan(2000). Satisfaction, consistency, and the space for policy effectiveness: A behavior analysis of foreign invested high-technology companies. Management World, (3)

Kang Rongping, Ke Yinbin (2002). Growth mode of Chinese multinational corporations. Management World, (2)

Kogut B, Zander U(1993). Knowledge of the firm and the evolutionary theory of the multinational enterprises. Journal of International Business Studies, 24: 625-646

Prahalad C K, Doz Y L(1987). The multinational mission: Balancing local demands and global vision. New York: The Free Press

Pfeffer J R, Salancik G R(1978). The external control of organizations. New York: Harper and Row

Qiu Licheng, Yu Lina(2003). An analysis of the pattern and antecedent factors of multinational corporations' entry into Chinese market. NanKai Economic Research. (4)

Sigglekow N(2001). Evolution toward fit. Administrative Science Quarterly, 47: 125-159

Simon H A(1955). A behavioral model of rational choice. Quarterly Journal of Economics, 69: 99-118

Spar D L(2001). National policies and domestic polices. In A. Rugman \& T. Brewer (eds.) The Oxford Handbook of International Business, Oxford: Oxford University Press, 206-231

Vermeulen F, Barkema H(2002). Pace, rhythm and scope: Process dependence in building a profitable multinational corporation. Strategic Management Journal, 23(7): 637-653

Wang Luolin, Jiang Xiaojuan, Lu Shengliang(2000a). Impact of the investment of large-scale multinational corporations on the industry structure, technological upgrading and economic globalization of Chinese industries (I) - An analysis based on the investment projects of firms listed in the Global 500. Industrial Economics in China, (4)

Wang Luolin, Jiang Xiaojuan, Lu Shengliang(2000b). Impact of the investment of large-scale multinational corporations on the industry structure, technological upgrading and economic globalization of Chinese industries (II) - An analysis based on the investment projects of firms listed in the Global 500. Industrial Economics in China, (5)

Wu Xiaoyun, Yuan Lei(2003). Development trend and choices of marketing strategies in the consumer electronics industry of China - A comment on the competitive strategy of multinational corporations in China and the marketing strategy of indigenous Chinese manufacturers. Management World, (10)

$\mathrm{Xu}$ Dean, Shenkar O(2002). Institutional distance and the multinational enterprise. Academy of Management Review, 27(4): 608-618

Xue Lan, Wang Jianmin (1999). Knowledge economy and the global integration of R\&D: the 
Challenges and opportunities faced by China. International Economic Review, (2)

Xue Lan, Wang Shugui, Shen Qunhong(2001). An analysis of the impact of industry-level factors on the establishment of R\&D units by MNCs in China. R\&D Management, 22(4)

Xue Lan, Shen Qunhong, Wang Shugui(2002). Pattern in the distribution of R\&D investment by MNCs in China as part of their global strategy: An empirical analysis on the industrial differences in the distribution of independent R\&D units established by MNCs in China. Management World, (3)

Yip G S(1995). Total Global Strategy. Upper Saddle River, NJ: Prentice-Hall

Zhao Jinghua(2001). The strategic roles and the evolving trend of the growth and development of MNC subsidiaries in China. Industrial Economics in China, (12)

Zhao Jinghua (2002). An empirical analysis of the growth and development of MNC subsidiaries in China. Management World, (10) 